\title{
Isolated Dandy-Walker malformation
}

INSERM

\section{Source}

INSERM. (1999). Orphanet: an online rare disease and orphan drug data base. Isolated Dandy-Walker malformation. ORPHA:217

Dandy-Walker malformation (DWM) is the association of three signs: hydrocephalus, partial or complete absence of the cerebellar vermis, and posterior fossa cyst contiguous with the fourth ventricle, presenting early in life with hydrocephalus, bulging occiput and posterior fossa signs such as cranial nerve palsies, nystag mus and ataxia. 